\title{
List of Committees
}

Financial support for I.A.U. Colloquium 107 from the following sources is gratefully acknowledged.

The International Astronomical Union

The Natural Sciences and Engineering Research Council of Canada

The Canadian Institute of Theoretical Astrophysics

The National Research Council of Canada

The Kluwer Publishing Corporation

The Dominion Astrophysical Observatory

The University of Victoria

Most of this money was used to assist 30 participants to cover the expenses associated with attending the Colloquium, and was thus of great importance to its success.

\section{SCIENTIFIC ORGANIZING COMMITTEE:}

$\mathrm{J}$. Andersen, Denmark

A.H. Batten, Canada

E. Budding, New Zealand

J.-P. De Greve, Belgium

M. Hack, Italy

R.W. Hilditch, U.K.

Y. Kondo, U.S.A.

M.I. Kumstashvili, U.S.S.R.

M.J. Plavec, U.S.A., Chairman

R.S. Polidan, U.S.A.

C.D. Scarfe, Canada

R.F. Sistero, Argentina

J. Smak, Poland

\section{LOCAL ORGANIZING COMMITTEE:}

A.H. Batten, Dominion Astrophysical observatory

R.J. Brown, University of Victoria

J.M. Fletcher, Dominion Astrophysical observatory

W.A. Fisher, Dominion Astrophysical Observatory

$\mathrm{J}$. Goudy, University of Victoria

R.M. Haapala, Dominion Astrophysical Observatory

R.M. Robb, University of Victoria

C.D. Scarfe, University of Victoria, Chairman

xvii 